Admittedly the critical evidence may be unobtainable; even so Ohno's discussion of chromosomal evolution reveals the strength of this type of approach, yet he neglects its inherent weakness. Evolution of genomes is also dealt with; it would have been helpful if a diagram had been supplied to "fix" the mass of facts presented, relating taxonomic position with DNA value within this cytologically rooted evolutionary tree. The first section ends with a useful comparison of $X$ and $Z$-linked genes between phylla. From the evidence presented it seems likely that both Adam and the Serpent carried similar genes on their sex chromosomes.

Tho second section deals with dosage compensation and "lyonization" of X chromosomes. This is discussed from a biochemical, morphological and cytological point of view. No mention is made of scepticism of this phenomenon and newcomers to the field may perhaps like to read Gı üneberg's views before completely digesting the inter pretation.

How do the sex chromosomes determine sex ? The last section attempts to answer this question and thereby to justify the book as a "Monograph on Endocrinology". But, as Ohno admits, no answers are forthcoming. This leads to an expectedly sketchy chapter on sex-determining factors. A second chapter on the development of gonads will, no doubt, resuscitate endocrinologists after the previous 160 pages of cytogenetics.

This is an attractively written and produced book and a veritable mine of information. Cytogeneticists will not be disappointed by Ohno's scholarship and authority. The many photographs and diagrams are of high quality although the photographs of Fig. 20 are unnumbered and should be viewed sideways on. There are a few typographical errors (for example, homozygous for homologous; page 102, end of first paragraph) and the potentially libellous phrase "mongolian idiocy" appears for Down's syndrome.

In all, this is a compulsively readable account of a subject hitherto badly in need of Ohno's capable treatment.

P. W. Barlow

\section{NORMAL AND ABNORMAL CELLS}

Practical Cytology

By R. G. W. Taylor. Pp. xi +148 . (London: Academic Press, Inc. (London), Ltd.; New York: Academic Press, Inc., 1967.) 39s. 6d.; $\$ 7$.

IN clinical medicine the term cytology has come to have rather a special meaning, namely the examination of cells as an aid to diagnosis with some stress on the detection of malignant and benign growths of the female reproductive tract. It may also be added that the term has a euphemistic value when dealing with patients, and indeed even when giving extra-mural lectures to unsuspecting women's organizations. It is not surprising, therefore, that a book bearing the general title Practical Cytology should have a restricted content, being almost entirely concerned with smear techniques in medicine with a marked bias towards their application in gynaecological disorders.

The first chapter deals with the preparation of smears; the theory of fixation on which any rational approach depends is limited to a single sentence: "The principal requisite of a cytological fixative is that it shall precipitate the cell protein, and in particular the nuclear protein in a pattern characteristic of the form during life". The staining, mounting and examining of smears appear in the next chapter. Here the author seems unsure of the background of his readers; the opening page deals en passant with Papanicolaou's solutions, the Jenner -Giemsa method, Feulgen's stain and "it must be remembered that methanol fixation is a pre-requisite for all Romanowsky sequences". A few pages farther on, there are sections entitled "Cleaning Smears", "Loading the Slide Carrier", "Blueing Smears" and so on. There are numerous staining schedules, with little explanation; but all rigidly and ponderously timed so that "most of the black magic associated with staining disappears".

A diagram of a general cell which marks the beginning of the third chapter is so abysmal as to defy further useful comment; it is also odd to see a detailed table designed so that the greater part of it actually appears upside down (the rest is printed sideways). T'his chapter, however, heralds the first of four others on normal and abnormal epithelial cells. The descriptions of the cells are clear and informative and there are some good, simple diagrams. The need for numerous photomicrographs has been recognized, but unfortunately these are generally of such mediocre quality that they do not help; none are in colour.

The last two chapters deal with documentation and ancillary techniques. There is a useful appendix and a brief bibliography.

The book really adds little to a subject which is itself fascinating and work which is rewarding. D. LACY

\section{MOLECULAR PHARMACOLOGY}

\section{Drugs Affecting the Peripheral Nervous System}

Vol. 1. Edited by Alfred Burger. (Medicinal Research: A Series of Monographs.) Pp. xxiii +620 . (London: Edward Arnold (Publishers), Ltd.; New York: Marcel Dekker, Inc., 1967.) 220s. net.

IT is fashionable nowadays to add the adjective molecular to many of the normal subdivisions of biology, and it is a nice semantic exercise to consider what is meant by this qualification in each of its various applications. Pharmacology is no exception and the expression "molecular pharmacology" is enjoying a current vogue although, rather more than in most cases, it is a tautology. Pharmacology has been faced with the problem, in its most acute form, of relating the biological and the molecular properties of drugs since its emergence as a separate: scientific discipline in the middle of the nineteenth century. By using purely empirical procedures a great array of potent and useful druga has been assembled, but our understanding of how these drugs act at the molecular level is still very slight, and has depended on collateral advances in other related subjects. This multi-author work collects together a geat deal of experimental evidence and attempts a survey of the ideas and theories currently deployed. Attention is restricted to the peripheral nervous system-a further volume dealing with the central nervous system is promised-and consequently covers much the same ground as D. J. Triggle attempted single-handed in his Chemical Aspects of the Autonomic Nervous System. Although it appears more than a year later the literature survey is not much more up to date, but this is a much more substantial work and the overall coverege is more exhaustive.

'The intention of the editor was to concentrate on the relationship between biological effect and chemical structure, but because of variations in the amount of material available and the personal preference of the various authors the balance of individual chapters varies within wide limits. The first chapter, by S. Ehrenpreis on cholinergic mechanisms, consists of a critical review of Nachmansohn's theory of the rolo of acetylcholine in nervous transmission followed by an interesting, if highly speculative, defence of the proposition that cholinesterase and the choline gic receptor are one and the same. At the other extreme is a very lorg chapter by L. Gyermek on $g$ anglion stimulant and depressant drugs, which consists of an exhaustive review of the many structure-action studies carried out with $\mathrm{g}$ inglion preparations with virtually no theoretical discussion.

There are two rather cursory chapters on eholinesterase, but the remainir $g$ articles on muscarinic and cholinolytic drugs, drugs acting on the skeletal neuromuscular junction, 